\title{
Analysis the 1978-2008 crustal and sub-crustal earthquake catalog of Vrancea region
}

\author{
L. Telesca ${ }^{1}$, V. Alcaz ${ }^{2}$, and I. Sandu ${ }^{2}$ \\ ${ }^{1}$ Consiglio Nazionale delle Ricerche, Istituto di Metodologie per l'Analisi Ambientale, C. da S. Loja, 85050 Tito (PZ), Italy \\ ${ }^{2}$ Moldavian Academy of Sciences, Institute of Geology and Seismology, Academiei str. 3, Chisinau, Moldova
}

Correspondence to: L. Telesca (luciano.telesca@imaa.cnr.it)

Received: 12 February 2012 - Accepted: 26 March 2012 - Published: 7 May 2012

\begin{abstract}
The crustal and sub-crustal seismicity that occurred in the Vrancea area from 1978 to 2008 is investigated. Due to quarry blast contamination, the analysis of the crustal seismicity was restricted to events that occurred between $20 \mathrm{~km}$ and $60 \mathrm{~km}$, considering sub-crustal events as all those that occurred at depths larger than $60 \mathrm{~km}$. The completeness magnitude was estimated between 2.3 and 2.5 for the crustal seismicity and between 2.9 and 3.1 for the sub-crustal one. The Gutenberg-Richter b-values show clear differences between crustal and sub-crustal seismicity, with values around 0.9 and 1.3-1.4, respectively. The analysis performed in this study represents a preliminary issue for the seismic hazard assessment of surrounding regions like Moldova, for which the earthquakes generated in Vrancea represent an important threat.
\end{abstract}

\section{Introduction}

Seismic hazard assessment depends mainly on earthquake catalogs. Several catalogs collect information on the Carpathian earthquakes: (i) the catalog of historical Romanian earthquakes, spanning over a millennium (984-1979) (Constantinescu and Mirza, 1980), provides 4 types of magnitudes, with minima ranging from 3 to 6 . (ii) The Radu Catalog (Radu, 1994) consists of the historical earthquakes with level of intensity $I_{0}>6$ and instrumental earthquakes with the level of $M>5.0$. (iii) Catalog of micro- earthquakes of intermediate-depth Vrancea region (Trifu and Radulian, 1991) collects all the earthquakes of Vrancea during 19741990, with minimum magnitude $M_{\mathrm{L}}$ of 2.1 . (iv) The cata$\log$ ROMPLUS (Oncescu et al., 1999) uses the seismic magnitude scale $M_{\mathrm{W}}$ for all the historical and instrumentally recorded seismic events. On the basis of the ROMPLUS catalog, 13 seismic active zones were identified in Romania (Marmureanu, 2009).
In this paper, we analyse the characteristics of the earthquake catalog ROMPLUS, but restricted to the focal zone Vrancea. This zone generates earthquakes that represent a major threat to the Republic of Moldova and neighbouring territories.

\section{Study area}

The seismotectonics of the South Eastern Carpathian Mountain arch and surrounding areas are reduced to three major tectonic units: East European Platform, Moesian and IntraAlpine Plates. Their contact, near the SE Carpathian Orogen, defines the seismic active zone of Vrancea (Cornea and Lazarescu, 1982; Sandulescu, 1984; Radulian et al., 2004). According to the instrumental observations, two categories of the Carpathian seismicity are identified: crustal and subcrustal (Radu and Polonic, 1982). The crustal seismicity of the Vrancea area is due to a series of active faults that have caused a high degree of crust fracturing (Oncescu and Trifu, 1987), while sub-crustal earthquakes occur on a slab, partially or completely detached from the continental crust in a weak sinking process (Wenzel et al., 1999; Radulian et al., 1999). The Vrancea seismic zone is characterized by maximal seismic activity at intermediate depths, with epicenters distributed within an ellipsoidal domain $60 \times 30 \mathrm{~km}^{2}$, rotated by azimuth $\theta \approx 45^{\circ}$ with respect to the major axis (Radu and Polonic, 1982; Constantinescu and Enescu, 1984). The recent relocation of several hypocenters of seismic events has increased the accuracy of the ellipsoidal domain to $90 \times 20 \mathrm{~km}^{2}$ (Radulian et al., 2007; Hurukawa et al., 2008). According to instrumental macroseismic data, the released seismic energy in the Carpathian area originated from the Vrancea seismic area accounts for about $93 \%$, of which $95 \%$ generated at intermediate depths (Radu and Polonic, 1982; Bala et al., 2003). 


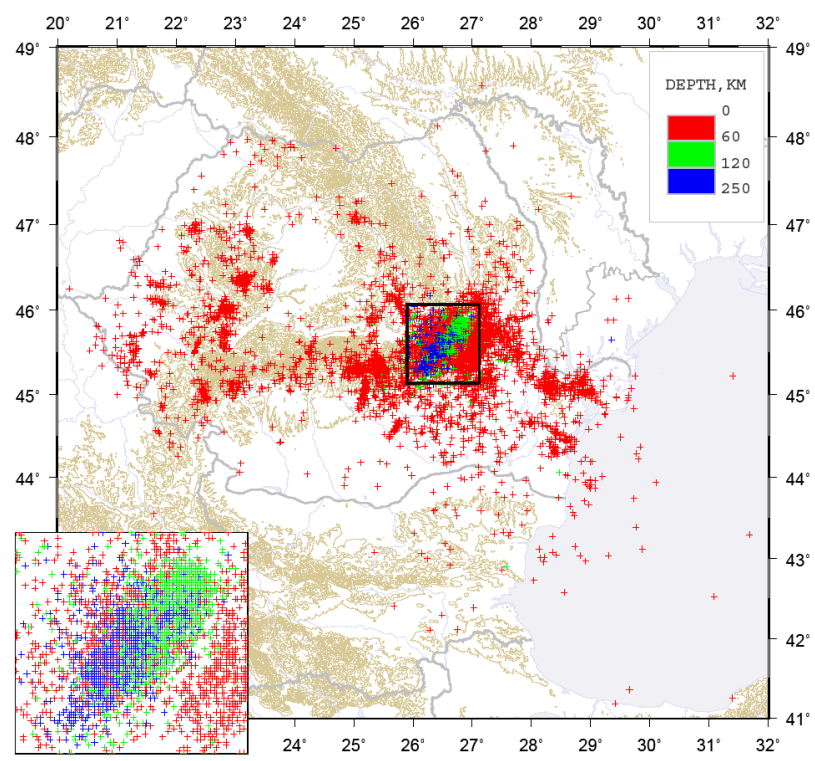

Fig. 1. Map of the seismicity of Vrancea from 1978 to 2008.

According to the ROMPLUS catalog, the maximum observed magnitude in the region was $M_{\mathrm{w}}=7.9$, corresponding to the 26 October 1802 earthquake. Several values for the maximum probable magnitude were obtained from the magnitude-foci fault geometry relationships: $M_{\mathrm{w}} \approx 8.1(\mathrm{Du}-$ bina and Lungu, 2003), $M_{\mathrm{w}}=7.9-8.0$ (Alcaz, 2007) and $M_{\mathrm{W}}=8.0$ (Wenzel et al., 1999). The mean recurrence interval $T$ as a function of the Gutenberg-Richter magnitude $M$ is $T \approx 80 \mathrm{yr}$, for $M \approx 7.5, T \approx 30 \mathrm{yr}$, for $M \approx 7.0, T \approx 10 \mathrm{yr}$, for $M \approx 6.5$ (Radu and Polonic, 1982; Alcaz, 2007).

\section{Analysis of the seismicity data}

We analysed the crustal and sub-crustal Vrancea seismicity that occurred from 1978 to 2008. Figure 1 shows spatial distribution of the investigated seismicity. The depth distribution is shown in Fig. 2 and reveals a minimum around $60 \mathrm{~km}$, which can be considered as separating the crustal and subcrustal events. Since the crustal seismicity could be generally affected by the presence of artificial events (quarry and mine blasts), removing such man-made contaminations represents an important issue to perform before seismicity analysis; in fact, artificial events could lead to a miscalculation of seismicity rates, of b-values of the Gutenberg and Richter law (Gutenberg and Richter, 1944) and erroneous micro-seismicity analysis (Giulia, 2010). Wiemer and Baer (2000) found that quarry blasts generally occur during daytime, and introduced the day-night-normalized ratio, defined as $D / N=\left(N_{\mathrm{d}} L_{\mathrm{n}}\right) /\left(L_{\mathrm{d}} N_{\mathrm{n}}\right)$, where $N_{\mathrm{d}}$ and $N_{\mathrm{n}}$ are the total number of events in the daytime and nighttime period, respectively; $L_{\mathrm{d}}$ is the number of hours in the daytime period and $L_{\mathrm{n}}$ those in the nighttime period. The evaluation of

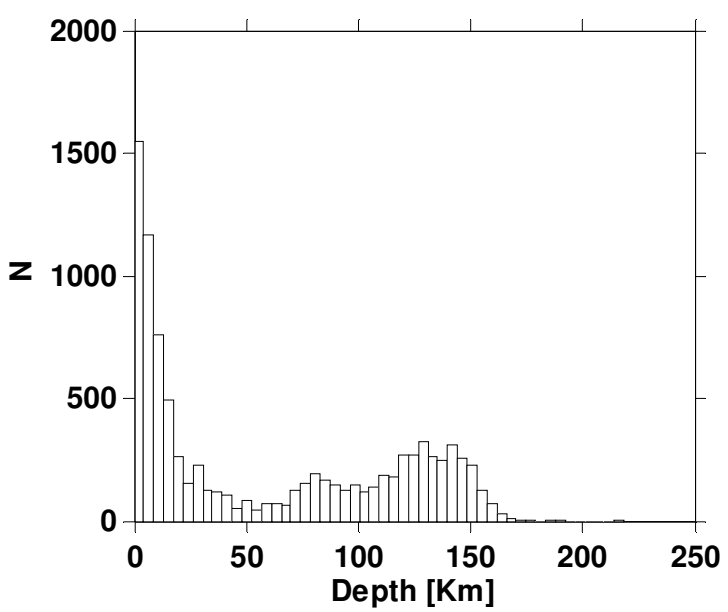

Fig. 2. Depth distribution of seismicity of Vrancea.

the artificial events should take into account both the magnitude, which is less than 2.5 for Europe (Giardini et al., 2004), and also the depth, because quarry and mine blasts occur within a few kilometers from the subsurface. We checked the homogeneity of the hourly distribution of the events for different values of the magnitude $m_{T}$ and depth $d_{T}$ (measured in $\mathrm{km}$ ) minimum thresholds. Figure 3 shows the hourdepth distribution and Fig. 4 shows the hour-magnitude distribution. A slice of the 3-dimensional histogram for a specific depth/magnitude furnishes the hourly distribution of the events for that specific depth/magnitude. It is clearly visible that the hourly distribution is rather homogeneous for depths larger than $20 \mathrm{~km}$ and for magnitudes higher than 2.5 . Anyway, the dishomogeneity in the hour-depth distribution seems larger than that in the hour-magnitude distribution. In order to disregard the possible quarry blasts, occurring in the shallower strata of the crust, we, then, investigated the crustal seismicity given by earthquakes occurring between $20 \mathrm{~km}$ and $60 \mathrm{~km}$.

The completeness magnitude $M_{\mathrm{c}}$ is defined as the lowest magnitude of the catalog at which all the events are reliably detected (Rydelek and Sacks, 1989). The estimate of $M_{\mathrm{c}}$ can be performed by several methods. In this study we used three methods:

1. the maximum curvature (MAXC) method (Wiemer and Wyss, 2000), in which the completeness magnitude is defined as the point where the first derivative of the frequency magnitude curve assumes its maximum (being the maximum of the non-cumulative frequencymagnitude distribution);

2. the goodness-of-fit (GFT) method (Wiemer and Wyss, 2000 ), in which the observed frequency-magnitude distribution is compared with synthetic distributions and the GFT is calculated as the absolute difference of the 


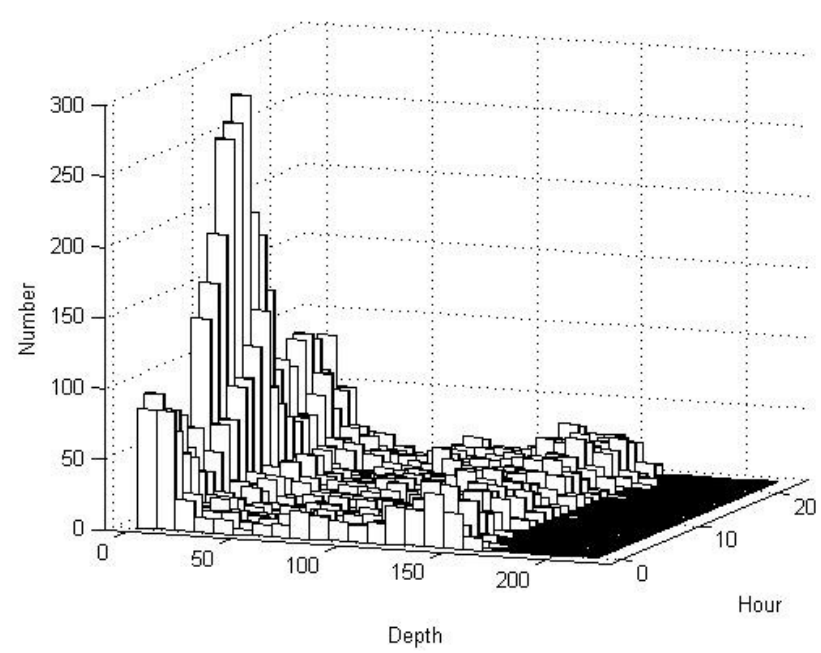

Fig. 3. Hour-depth distribution of Vrancea earthquakes.

number of earthquakes in the magnitude bins between the observed and synthetic distribution. Synthetic distributions are calculated using estimated a- and b-values of the Gutenberg-Richter law for the observed dataset increasing the cutoff magnitude; the completeness magnitude, thus, is given by that cutoff magnitude value, at which the $90 \%$ of the observed data is modelled by a straight line;

3. the entire magnitude range (EMR) method, firstly developed by Ogata and Katsura (1993) and then modified by Woessner and Wiemer (2005). A maximum likelihood estimation is used for a model, which comprises the complete (modelled as a power-law distribution) as well as the incomplete (modelled as a normal distribution) part of the frequency-magnitude distribution. The complete part is characterized by the Gutenberg-Richter law parameters, $a$ and $b$, while the incomplete part by the parameters $\mu$, which is the magnitude at which $50 \%$ of the earthquakes are detected, and $\sigma$ that is the standard deviation describing the width of the range where earthquakes are partially detected. By using the maximum likelihood estimation method all the parameters are calculated.

All the described methods are implemented in the Matlab software ZMAP (Wiemer, 2001). Figure 5 shows the number of earthquakes versus magnitude for the crustal (Fig. 5a) and sub-crustal (Fig. 5b) seismicity. The completeness magnitude of the crustal seismicity is 2.3 (with the MAXC and GFT methods) and 2.5 (with the EMR method), while that of the sub-crustal seismicity is 2.9 (with the MAXC and GFT methods) and 3.1 (with the EMR method). The difference between the values of the completeness magnitude in both catalogs is only 0.2 and this indicates that all three methods give approximately consistent values for the completeness

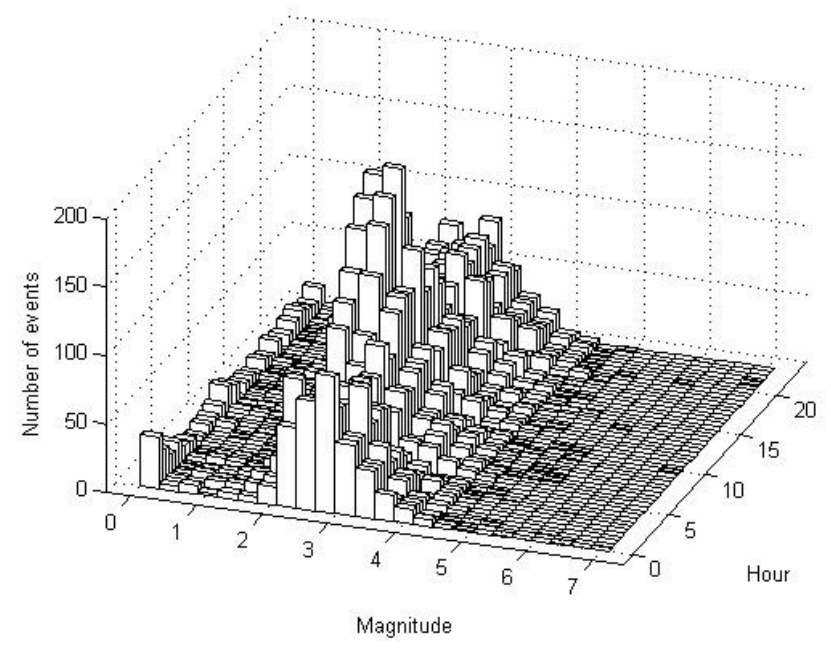

Fig. 4. Hour-magnitude distribution of Vrancea earthquakes.

magnitude. The values obtained are in good accordance with those indicated in Marmureanu(2009) and obtained on the basis of the maximum of the non-cumulative frequencymagnitude distribution: $M_{\mathrm{c}}=2.4$ and $M_{\mathrm{c}}=3.0$ for crustal and sub-crustal seismicity, respectively.

The estimation of the b-value of the Gutenberg-Richter law was performed by means of the maximum likelihood estimation method (Aki, 1965), $b=\log _{10}(e) /[<M>$ $\left.-M_{\mathrm{c}}+0.05\right]$, where $<M>$ indicates the average of the magnitudes of the sample, $M_{\mathrm{c}}$ the completeness magnitude and 0.05 is the magnitude correction. Since the completeness magnitude is in the formula, the b-value depends on the method used to estimate $M_{\mathrm{c}}$. In particular for the sub-crustal catalog, we get $b=0.942 \pm 0.02$ (EMR) and $b=0.879 \pm 0.01$ (MAXC and GFT), while for the crustal catalog we obtain $b=1.30 \pm 0.05$ (MAXC and GFT) and $b=1.48 \pm 0.08$ (EMR). Also regarding the $b$-value, all the methods furnish consistent values.

\section{Conclusions}

The aims of the present study were (i) checking for the quarry blast contamination, (ii) estimation of the completeness magnitude, and (iii) estimation of the b-value in Vrancea region, which is one of the most seismically active zones in Eastern Europe, where generated earthquakes constitute a source of relevant damage even in aseismic surrounding areas like the Republic of Moldova. The analysis was performed on the crustal and sub-crustal seismicity, whose border can be placed at a depth of about $60 \mathrm{~km}$. The analysis of the hour-depth and hour-magnitude distributions has suggested that crustal seismicity is not influenced by quarry blasts for events that occurred at depths between $20 \mathrm{~km}$ and $60 \mathrm{~km}$. The crustal and sub-crustal catalogs appear complete for events with a magnitude larger than 2.3-2.5 and 


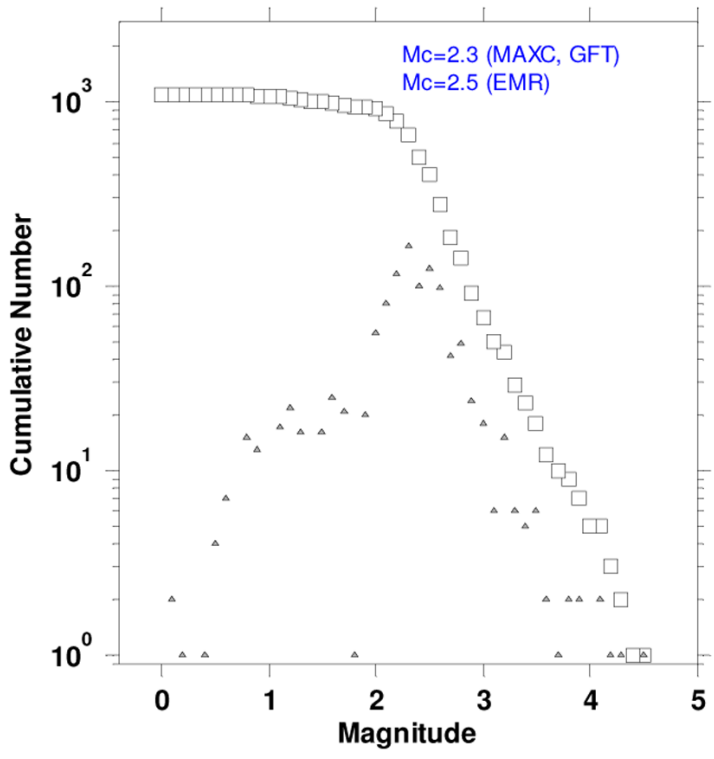

a)

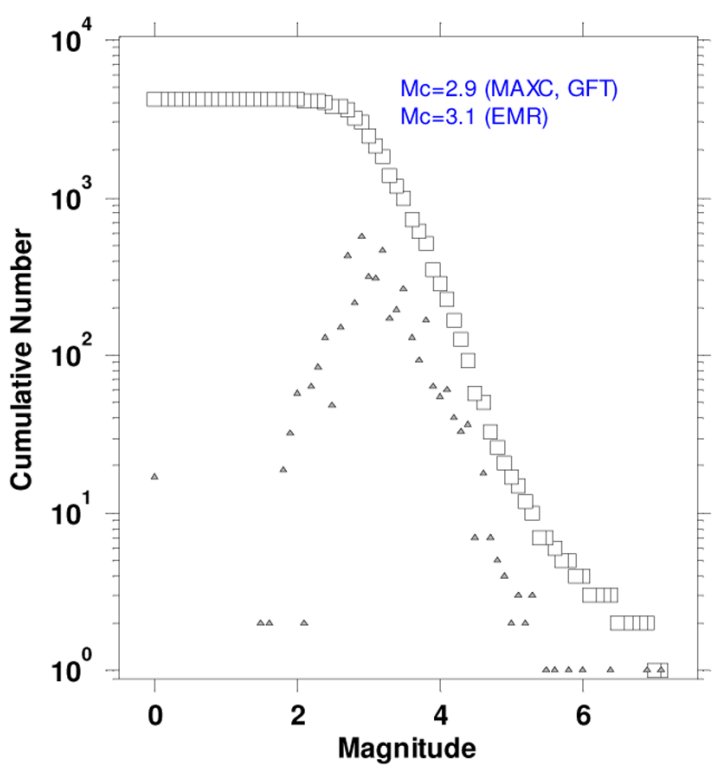

b)

Fig. 5. Frequency-magnitude distribution of (a) crustal and (b) subcrustal Vrancea seismicity.

2.9-3.1, respectively. Differences in the seismic b-values were found between crustal and sub-crustal seismicity, with values around $1.3-1.5$ and 0.9 , respectively, indicating differences in the state of stress and/or in material properties. Then $b$ could be able to provide evidence of inhomogeneities in seismogenic fault areas that can be attributed to potential asperities (Sobiesiak et al., 2007). Therefore, the difference in the b-values between crustal and sub-crustal seismicity could be a clear indication of heterogeneity of either a stress field, or different material properties in the seismogenic zone for strata shallower or deeper than $60 \mathrm{~km}$. The lower b-value dominating the sub-crustal seismicity is also consistent with the main ruptures that have occurred at these depths.
Acknowledgements. The present study was supported by the CNR/ASM 2011-2012 Project "Characterization of seismicity of Moldova Republic territory. Contribution to seismic hazard assessment".

Edited by: M. E. Contadakis

Reviewed by: I. Paskaleva and another anonymous referee

\section{References}

Aki, K.: Maximum likelihood estimate of $b$ in the formula log $\mathrm{N}=\mathrm{a}-\mathrm{bM}$ and its confidence limits, Bull. Earthq. Res. Inst. Tokyo Univ., 43, 237-239, 1965.

Alcaz, V. G.: Seismic Hazard and Risk Forecast for Republic Moldova Territory, Chisinau, Elena, 230 pp., 2007 (in Russian).

Bala, A., Radulian, M., and Popescu, E.: Earthquake distribution and their focal mechanism in correlation with the active tectonic zones of Romania, J. Geodynam., 36, 129-145, 2003.

Constantinescu, L. and Enescu, D.: A tentative approach to possibly explaining the occurrence of the Vrancea earthquakes, Rev Roum. de Geol. Geophys. Geogr. Geophys., 28, 19-32, 1984.

Constantinescu, L. and Marza, V.: A computer-compiled and computer-oriented catalogue of Romania's earthquakes during a millennium, Rev. Roum. Geophys. 24, 193-234, 1980.

Cornea, I. and Lazarescu, V.: Geology and seismotectonics of Romania, The March 4, 1977 Earthquake in Romania, Academy Press, Bucharest, 19-35, 1982.

Dubina, D. and Lungu, D.: Hazard, Vulnerabilitaty and Seismic Risk, Buildings located in seismic strong motion areas, ISBN 9738391903, Timisoara, Orizonturi Universitare Press, Romania, 23-74, 2003.

Giardini, D., Wiemer, S., Fäh, D., and Deichmann, D.: Seismic hazard assessment of Switzerland, Report, Swiss Seismological Service, ETH Zurich, 88 pp., 2004.

Giulia, L.: Detection of quarry and mine blast contamination in European regional catalogues, Nat. Hazards, 53, 229-249, 2010.

Gutenberg, B. and Richter, C. F.: Frequency of earthquakes in California, Bull. Seism. Soc. Am., 34, 185-188, 1944.

Hurukawa, N., Popa, M., and Radulian, M.: Relocation of large intermediate-depth earthquakes in Vrancea region, Romania, since 1934 and a seismic gap, Earth Planet. Space, 60, 565-572, 2008.

Marmureanu, Gh. (coordinator): Research of disaster management generated by romanian earthquakes, Tehnopress, Iasi, $766 \mathrm{pp}$., 2009 (in Romanian).

Ogata, Y. and Katsura, K.: Analysis of temporal and spatial heterogeneity of magnitude frequency distribution inferred from earthquake catalogs, Geophys. J. Int., 113, 727-738, 1993.

Oncescu, M. C., Mirza, V., Rizescu, M., and Popa, M.: The Romanian earthquake catalogue between 994-1997, Vrancea Earthquakes: Tectonics, Hazard and Risk Mitigation, edited by: Wenzel, F. and Lungu, D., Ser.: Advances in Natural and Technological Hazards Research, Kluwer Academic Publishers, 43-47, 1999.

Oncescu, M. C. and Trifu, C. I.: Depth variation of the moment tensor principal axes in Vrancea (Romania) seismic region, Ann. Geophys., 5B, 149-154, 1987.

Radu, C.: Catalogues of earthquakes occured on Romanian territory during the periods 984-1990 and 1901-1994, manuscripts, 1994. 
Radu, C. and Polonic, G.: Seismicity of Romanian territory with special reference to Vrancea region, The March 4, 1977 Earthquake in Romania, Academy Press, Bucharest, 75-136, 1982.

Radulian, M., Mandrescu, N., Popescu, E., Utale, A., and Panza, G. F.: Seismic activity and stress field in Romania, Romanian J. Phys., 44, 1051-1069, 1999.

Radulian, M., Bala, A., and Popescu, E.: Fault Plane Solution as Indicators of Specific Stress Field Characteristics in Vrancea and Adjiacent Seismogenic Zones, edited by: Lungu, D., Wenzel, F., Mouroux, P., and Tojo, I., Proceedings of International Conference Earthquake Loss Estimation and Risk Reduction, Bucharest, Romania, 151-161, 2004.

Radulian, M., Bonjer, K.-P., Popa, M., and Popescu, E.: Seismicity patterns in SE Carpathians at crustal and subcrustal domains: tectonic and geodynamic implications, Proc. CRC-461 Int. Symposium on Strong Vrancea Earthquakes and Risk Mitigation, MATRIX ROM, Bucharest, 93-102, 2007.

Rydelek, P. A. and Sacks, I. S.: Testing the completeness of earthquake catalogues and the hypothesis of self-similarity, Nature, 337, 251-253, 1989.

Sandulescu, M.: Geotectonics of Romania, Technical Publishing House, Bucharest, 335 pp., 1984.

Sobiesiak, M. M., Meyer, U., Schmidt, S., Götze, H. J., and Krawczyk, C.: Asperity generating upper crustal sources revealed by b-value and isostatic residual anomaly grids in the area of Antofagasta, J. Geophys. Res., 112, B12308, doi:10.1029/2006JB004796, 2007.
Trifu, C. I. and Radulian, M.: Depth-magnitude catalogue of Vrancea intermediate depth microearthquakes, Rev. Roum. Geophys., Academy Press, Romania, 35, 31-45, 1991.

Wenzel, F., Lorentz, F. P., Sperner, B., and Oncescu, M. C: Seismotectonics of the Romanian Vrancea Area, in: Vrancea Earthquakes, Tectonics, Hazard and Risk Mitigation, Ser.: Advances in Natural and Technological Hazards Research, Kluver Academic Publishers, 15-25, 1999.

Wiemer, S.: A software package to analyze seismicity: ZMAP, Seismol. Res. Lett., 72, 374-383, 2001.

Wiemer, S. and Baer, M.: Mapping and removing quarry blast events from seismicity catalogs, Bull. Seism. Soc. Am., 90, 525530, 2000.

Wiemer, S. and Wyss, M.: Minimum magnitude of complete reporting in earthquake catalogs: examples from Alaska, the Western United States, and Japan, Bull. Seism. Soc. Am. 90, 859-869, 2000.

Woessner, J. and Wiemer, S.: Assessing the Quality of Earthquake Catalogues: Estimating the Magnitude of Completeness and Its Uncertainty, Bull. Seismol. Soc. Am., 95, 684-698, doi:10.1785/0120040007, 2005. 